\title{
FE-SEM examination of Microalloyed Hypereutectoid Steels
}

\author{
A. M. Elwazri, R. Gauvin and S. Yue \\ Department of Mining and Metals and Materials Engineering, McGill University 3610 \\ University St. Montreal, QC, Canada, H3A 2B2.
}

Field Emission Scanning Electron Microscopy (FE-SEM) is a high-resolution imaging technique providing topographic and structural information in plan view or in crosssection. Used in conjunction with SEM, Energy Dispersive X-Ray Spectroscopy (EDX) is used to qualitatively and quantitatively analyze the elements present in a selected area of the SEM image.

With the appropriate lens set up, FE-SEM is a powerful tool for detection of fine precipitates. For microalloyed steels, the usual approach for fine precipitate characterization is transmission electron microscopy. However, TEM specimen preparation is usually much more involved than that for SEM specimens. Moreover, for steels with considerable levels of pearlite, both thin foil and extraction replica preparation are problematic, since cementite is not easily attacked by the etchants and polishes that attack ferrite. Thus, this work was initiated to determine the feasibility of characterizing precipitates in hypereutectoid steel using FE-SEM.

Two hypereutectoid steels of $1 \%$ carbon, with vanadium and without vanadium were used; compositions are shown in Table I. The specimens were austenitised for $20 \mathrm{~min}$ at $1200^{\circ} \mathrm{C}$. The transformation of the austenite was then carried out in a salt bath 550,580 and $620^{\circ} \mathrm{C}$. The specimens were kept in the salt bath for $10 \mathrm{~min}$, after which time transformation was complete; these were then water quenched. The specimens were automatically polished using successively finer silicon carbide paper from 60 to 1200 grit and fine polishing with $3 \mu \mathrm{m}$ and $1 \mu \mathrm{m}$ diamond solution. The microstructures were then revealed by etching in $3 \%$ Nital.

Figure (1) shows the microstructure of steel without vanadium; the interlamellar structure of pearlite can be observed, but no precipitates in the interlamellar regions can be seen. In the case of the vanadium bearing steel, as shown in Figure (2), many precipitates can be clearly seen. Some of these are in the tens of nanometer range. Since the only major difference between these two steels is $\mathrm{V}$, then the assumption is that the precipitates contain V. Figure 3 is an EDS analysis of one of the larger precipitates. Unfortunately, it is difficult to resolve the $\mathrm{V}$ from the $\mathrm{Cr}$ peak. However, $\mathrm{Cr}$ is present in both steels, and precipitates were not observed in the steel without $\mathrm{V}$. It is possible that $\mathrm{V}$ and $\mathrm{Cr}$ are combining to form complex carbides, but this obviously needs more analyses to clarify the composition of these precipitates. In any case, this result shows clearly that the FESEM technique is an appropriate tool in characterizing the precipitates of steels containing large volume fractions of pearlite.

\section{Table I Chemical composition of experimental steels}

\begin{tabular}{|l|l|l|l|l|l|l|}
\hline Steel & $\mathrm{C}$ & $\mathrm{Si}$ & $\mathrm{Mn}$ & $\mathrm{Cr}$ & $\mathrm{V}$ & $\mathrm{N}$ \\
\hline V1 & 1.1 & 0.23 & 0.63 & 0.066 & 0.17 & 0.007 \\
\hline V0 & 0.91 & 0.21 & 0.49 & 0.04 & 0.00 & 0.0031 \\
\hline
\end{tabular}



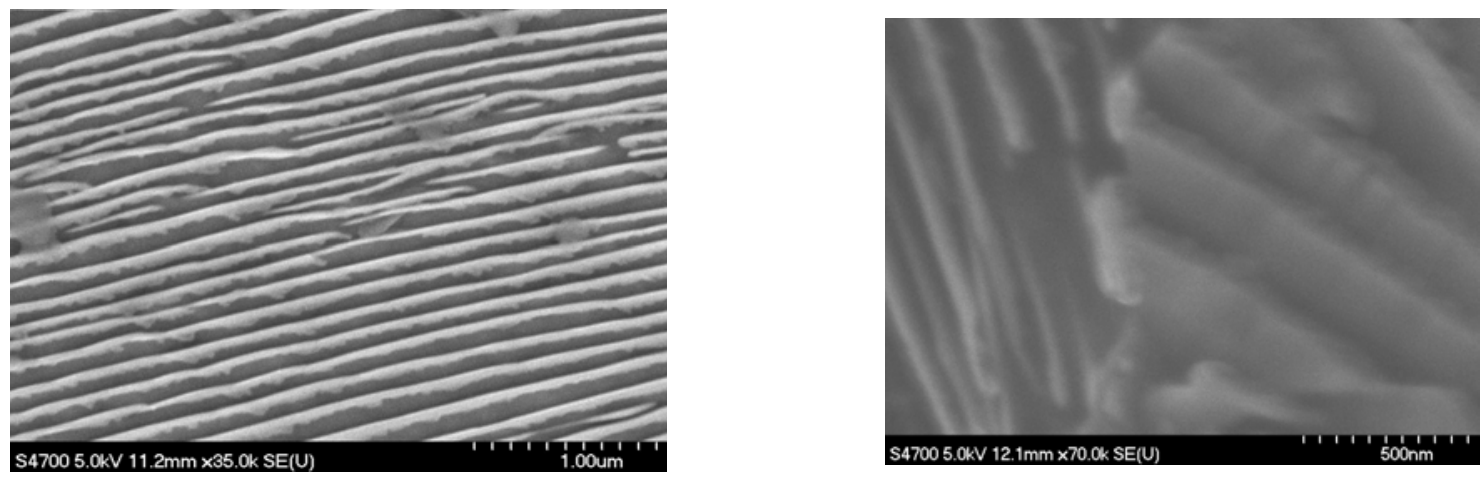

Figure (1) Hypereutectoid steel without vanadium (etching)
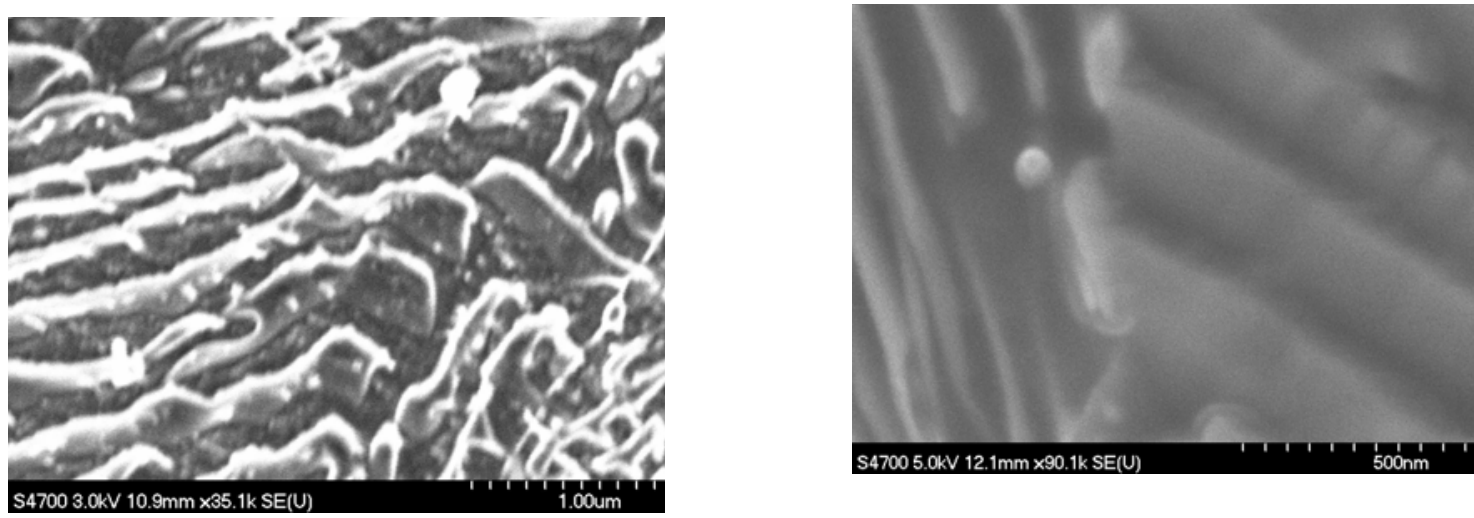

Figure (2) Hypereutectoid steel with vanadium (etching). Precipitates, nano sized and greater, can be observed.

Figure (3) Detail of EDS spectrum of one of the precipitates of Figure (2). The $\mathrm{V}$ and $\mathrm{Cr}$ peaks are convoluted.

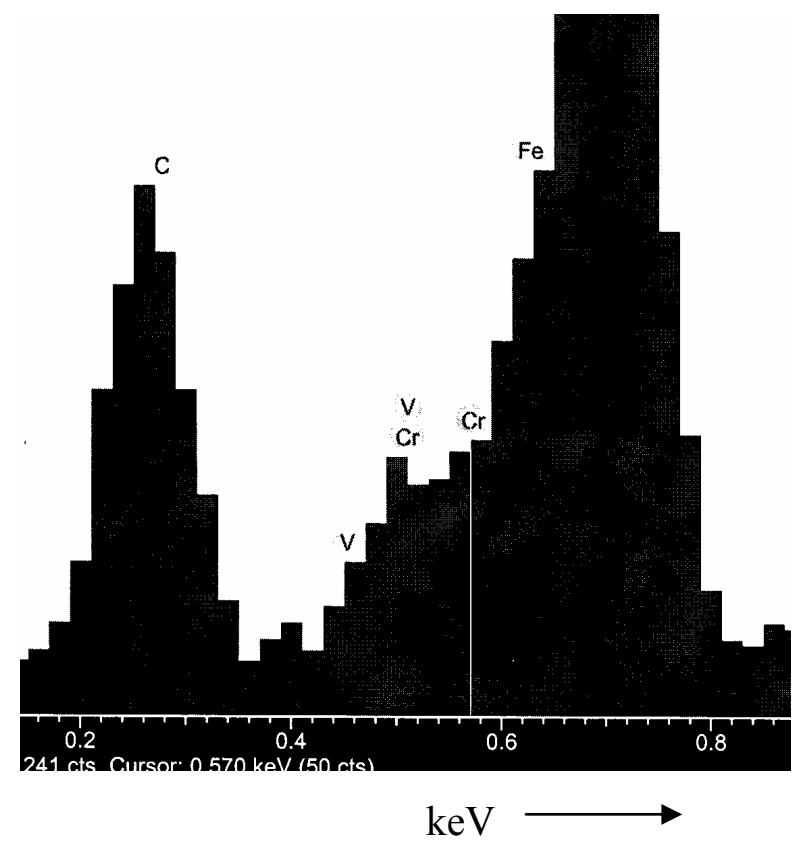

